\title{
Alpha-Glucosidase Inhibitory Activity and Fractionation of Bioactive Compounds from bark Extracts of Sibucao (Caesalpinia sappan L.) In the Philippines
}

\author{
Ea Kristine Clarisse B. Tulin, Ma Theresa P. Loreto, Edgardo E. Tulin
}

\section{Ea Kristine Clarisse B. Tulin, Ma Theresa P. Loreto, Edgardo E. Tulin}

Department of Biotechnology, Visayas State University, President, Visayas State University, PHILIPPINES.

\section{Correspondence}

Ea Kristine Clarisse B. Tulin

President's cottage, Visayas State University, Baybay City, Leyte 6521, PHILIPPINES.

Phone no: 9068090478

E-mail: eakristine8995@gmail.com

History

- Submission Date: 16-12-16;

- Review completed: 05-01-17

- Accepted Date: 27-02-17.

DOI : 10.5530/pj.2017.3.60

Article Available online http://www.phcogj.com/v9/i3

\section{Copyright}

(C) 2017 Phcog.Net. This is an openaccess article distributed under the terms of the Creative Commons Attribution 4.0 International license.

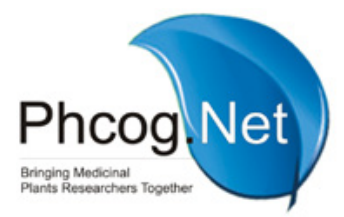

\begin{abstract}
Diabetes is a chronic disease that affects millions of people around the world. Although conventional medicine is available, it is usually accompanied by serious side effects such as gastrointestinal problem. Thus, the search for alternative medicine from natural sources is of primary importance. Context: The study is concerned with Caesalpinia sappan L. found in the vicinity of Baybay City, Leyte Philippines. Furthermore, it deals with ethanolic and aqueous extracts of the bark only. It was conducted to determine the alpha-glucosidase inhibitory activity of $C$. sappan to provide evidence to support its efficacy as a folkloric medicinal plant. Aims: This work aimed to evaluate the alpha-glucosidase inhibitory activity of aqueous and ethanolic bark extracts of Sibucao (Caesalpinia sappan L.) and to partially fractionate its bioactive compounds. Settings and Design: Extracts were prepared in increasing concentration to get $\mathrm{IC}_{50}$ values. Samples were analysed in triplicate both for extracts and fractions collected from chromatography. Methods and Material: Caesalpinia sappan L. bark samples were collected from the vicinity of Visayas State University. Plant materials were dried, weighed and stored. Aqueous and ethanolic bark extracts were prepared using water and $20 \%$ ethanol. The total phenolic content of the extracts were determined and the $\alpha$-glucosidase inhibitory activity of crude bark and aqueous extracts were measured using the method of Kim et al., 2011. Partial fractionation of bioactive compounds was done successively using gradient elution. The $\alpha$-glucosidase inhibitory activity of fractions were then determined and Rf values of active compounds were measured using thin layer chromatography (TLC). Results: Results revealed that aqueous extract $(2000 \mathrm{ppm})$ and ethanolic extract $(2000 \mathrm{ppm})$ show high $\alpha$-glucosidase inhibitory activity of $100 \%$ and $59 \%$ respectively. $I C_{50}$ values of aqueous and ethanolic extract were found to be $300.52 \pm 1.467 \mathrm{ppm}$ and $1560.81 \pm$ $2.582 \mathrm{ppm}$, respectively. TLC of fractions show 7 peaks for aqueous extract and 6 peaks for ethanolic extract in which compound with Rf value 0.70 had the highest inhibitory activity of $65 \%$. Conclusions: Taken together, the high $\alpha$-glucosidase inhibitory activity of aqueous extracts support the effectiveness of $C$. sappan L. bark decoctions. In addition, results from bioassay-guided fractionation can be used as an effective tool for further isolation and characterization of $\alpha$-glucosidase inhibitors from Caesalpinia sappan L. in the Philippines.
\end{abstract}

Key words: Caesalpinia sappan, $\alpha$-glucosidase, Type II diabetes, Flavonoids, Fractionation.

Key Messages: Caesalpinia sappan L. (Sibucao/sappanwood) is used in the islands of the Philippines as folkloric treatment to various ailments including diabetes. This study gives evidence to support the efficacy of bark decoctions of this plant and further shows its potential for medical applications.

\section{INTRODUCTION}

Conventional medicine of diabetes mellitus available in the market today work by inhibiting $\alpha$-glucosidase and $\alpha$-amylase enzymes. ${ }^{1}$ Plant extracts are known to possess many therapeutic properties including aglucosidase inhibitors. ${ }^{2}$ Sibucao (Caesalpinnia sappan L.) a plant native to the Philippines has been traditionally used by local healers in the Philippines ${ }^{3}$ and Southeast Asia ${ }^{4}$ to cure various ailments. This study was conducted to determine the a-glucosidase inhibitory activity of C. sappan L. bark extracts, compare enzyme inhibitory activity of aqueous and ethanolic extracts of C. sappan L. bark and partially purify and test bioactive compounds responsible for a-glucosidase inhibition.

\section{Subjects and Methods}

\section{Chemicals}

a-glucosidase (Saccharomyces cerevisiae), 4-Nitrophenyl a-D-glucopyranoside (PNPG), Dimethylsulfoxide (DMSO), Standard gallic acid and Acarbose $(\geq 95 \%)$ were purchased from Sigma-Aldrich, Singapore. Anhydrous sodium carbonate $\left(\mathrm{Na}_{2} \mathrm{CO}_{3}\right)$ and Folin-Ciocalteu's phenol reagent were purchased from Merck Millipore, Philippines.

\section{Collection of bark samples}

Bark samples of Sibucao (Caesalpinia sappan L.) were collected from verified samples within the area of the Visayas State University, Baybay City, Leyte, Philippines. This was done by scraping portions of the bark

Cite this Article: Tulin EKCB, Loreto MTP, Tulin EE. Alpha-Glucosidase Inhibitory Activity and Fractionation of Bioactive Compounds from bark Extracts of Sibucao (Caesalpinia sappan L.) In the Philippines. Pharmacogn J. 2017:9(3):356-60. 
off the trunk or the branch of the tree. Only the bark part of the tree was used in this experiment.

\section{Preparation of aqueous and ethanolic crude bark extracts}

The collected bark samples were washed with distilled water and ovendried at $40^{\circ} \mathrm{C}$ for 24 hours. The weight of fresh sample and the weight of dried sample were recorded and percent moisture was determined prior to extraction. Aqueous and ethanolic extracts were prepared using the method of Jyothi et al., 2011.5 One hundred grams of dried and ground bark was macerated with $500 \mathrm{~mL}$ of solvent, sterile distilled water for aqueous extract and $20 \%$ ethanol for ethanolic extract, in a heavy duty homogenizer for 15 minutes. The suspension was filtered through a double layer muslin cloth and then centrifuged at $5000 \mathrm{rpm}$ for 15 minutes. The supernatant was filtered using Whatman no.1 filter paper and the extracts were concentrated using a speedvac concentrator at $40^{\circ} \mathrm{C}$ and then preserved aseptically at $4^{\circ} \mathrm{C}$ until further use. Prior to the assay, the extracts were filtered using a 20 micron filter to remove possible microbial contaminants.

\section{Total phenolic content of plant extracts}

Crude extracts were reconstituted with dimethylsulfoxide (DMSO) and total phenolic concentration of sample was determined using the method by Singleton et al.,(1999) ${ }^{6}$ with some modifications. Standard gallic acid solutions of $12.5 \mathrm{ppm}, 25 \mathrm{ppm}, 50 \mathrm{ppm}, 100 \mathrm{ppm}, 200 \mathrm{ppm}$ and $500 \mathrm{ppm}$ concentrations were prepared. About $0.5 \mathrm{~mL}$ of the sample was added with $2.5 \mathrm{~mL}$ Folin-Ciocalteu solution (1:10 dilution with water) and $2.5 \mathrm{~mL} \mathrm{Na}_{2} \mathrm{CO}_{3}(75 \mathrm{~g} / \mathrm{L})$. The mixture was allowed to react for 30 $\min$ at $25^{\circ} \mathrm{C}$. Absorbance was read at $765 \mathrm{~nm}$ using UV-Vis spectrophotometer and concentration of extract were determined using the standard calibration curve.

\section{Evaluation of alpha-glucosidase inhibitory activity}

The method used to evaluate the inhibitory activity of C.sappan was based on Kim et al. (2011). ${ }^{7}$ Concentrated aqueous and ethanolic extracts were reconstituted with distilled water and DMSO, respectively, at $100 \mathrm{ppm}, 500 \mathrm{ppm}, 1000 \mathrm{ppm}$ and $2000 \mathrm{ppm}$ concentrations. Extracts $(50 \mu \mathrm{L}$, at different concentrations) were incubated with $\alpha$-glucosidase $(50 \mu \mathrm{L}, 0.5$ Units $/ \mathrm{mL})$ and $0.2 \mathrm{M}$ potassium phosphate buffer $(50 \mu \mathrm{L}, \mathrm{pH}$ $6.8)$ at $37^{\circ} \mathrm{C}$ in a waterbath for $15 \mathrm{~min}$. Then, $100 \mu \mathrm{L}$ of $3 \mathrm{mM} \mathrm{p}$-nitrophenyl glucopyranoside (PNPG) was added as substrate. The reaction was incubated again for ten minutes and then stopped by the addition of $750 \mu \mathrm{L}$ of $0.1 \mathrm{M} \mathrm{Na}_{2} \mathrm{CO}_{3}$. The absorption of 4-nitrophenol, a product after reaction, was measured at $405 \mathrm{~nm}$ using a UV-Vis spectrophotometer. Reaction mixture without the sample served as negative control and reaction mixture without the substrate served as blank. This experiment was performed in triplicate. Acarbose was used as positive control.

The percentage inhibition of $\alpha$-glucosidase was computed as follows: Inhibition rate $(\%)=\{1-($ Abs S-Abs B $) / A b s \mathrm{C}\} \times 100$

where: $\mathrm{Abs} \mathrm{S}=$ absorbance of the experimental sample,

Abs B = absorbance of the blank

Abs $\mathrm{C}=$ absorbance of the negative control

\section{Chromatographic separation of bioactive compounds using column chromatography (Shiny et al., 2013) ${ }^{8}$}

Crude extracts were evaporated in vacuo using a speedvac and the concentrate (pellet) was resuspended in absolute ethanol, at 1:1 ratio. Glass chromatographic column (15 cm long and $1.5 \mathrm{~cm}$ diameter) was prepared using silica gel (packed $9.0 \mathrm{~cm}$ long) equilibrated with three column volumes of hexane. Gradient elution with increasing polarity was done and fifteen fractions of one $\mathrm{mL}$ volumes each were collected. Table 1 shows the solvent systems used and the corresponding fraction num- ber. Fractions were further tested for its $\alpha$-glucosidase inhibitory activities using the previously described inhibition assay.

\section{Thin layer chromatography (Shiny et al., 2013)}

For thin layer chromatography, fractions were evaporated in vacuo using a speedvac and the resulting concentrate was resuspended in ethanol. Silica gel 60 F 254 plate $(20 \mathrm{~cm}$ x $20 \mathrm{~cm})$ was used as the stationary phase and hexane and ethanol in a 9:1 ratio was used as the mobile phase. The samples that were used are the solvent alone and fractions collected. The samples $(2 \mu \mathrm{L})$ were spotted on TLC plates at an equal distance of one $\mathrm{cm}$. Thereafter, the plates were viewed in UV light at $245 \mathrm{~nm}$ and spots were properly documented. Rf values were calculated after viewing the chromatogram using the formula

$$
R f=\frac{\text { Distance }(\mathrm{cm}) \text { from the origin to the center of substance spot }}{\text { Distance }(\mathrm{cm}) \text { from origin to solvent front }}
$$

\section{RESULTS}

\section{Moisture content of plant sample}

After oven-drying at $40^{\circ} \mathrm{C}$ for 26 hours the bark extract had a moisture content of $36.80 \%$. Moisture content analysis of a plant sample is important since it indicates the quality of material. In addition, when extracting phytochemicals from plant sample it is necessary to use dried samples as to inhibit the degradation of compounds and to aid in long term storage or preservation of sample. ${ }^{9}$

\section{Total phenolic content}

The phenolic content of aqueous and ethanolic extract was determined to have a baseline concentration of phenolic compounds in the sample. Phenolic content was used as basis of varying concentration since most a-glucosidase inhibitors derived from plant extracts are phenolic in nature. ${ }^{10,11,12}$ Moreover, flavonoids have also been known to possess hypoglycemic activity. ${ }^{13}$

\section{Alpha-glucosidase inhibitory activity of aqueous and ethanolic extracts}

Table 3 shows the $a$-glucosidase inhibitory activity of ethanolic and aqueous extracts at phenolic concentrations of $100 \mathrm{ppm}, 500 \mathrm{ppm}, 1000$ ppm and $2000 \mathrm{ppm}$. The $\mathrm{IC}_{50}$ value for ethanolic extracts is $1569.81 \pm$ $2.582 \mathrm{ppm}$ and for aqueous extracts is $300.52 \pm 1.467 \mathrm{ppm}$.

extracts at different concentrations

Figure 1 shows the graphical representation of the alpha-glucosidase inhibitory activity of aqueous and ethanolic extracts at different concentrations. Furthermore, it shows the dose-dependent response of the extracts Table 4 illustrates the $\alpha$-glucosidase inhibitory activity of the positive control Acarbose at different concentrations. The evaluation of alphaglucosidase inhibitory activity of acarbose was done to assess the validity of assay used. The concentration of Acarbose needed to inhibit a-glucosidase activity by half is $0.02043 \mathrm{ppm}$.

\section{Bio-assay guided fractionation of aqueous extracts}

To fractionate bioactive compounds, column chromatography was done using 15 solvent sytems and 15 fractions from aqueous extract were collected. Figure 2 shows the thin layer chromatogram (TLC) of the collected aqueous fractions while Table 5 shows the corresponding fraction number, inhibitory activity, Rf value and solvent system used in chromatographic separation of aqueous extracts. 
Table 1: List of solvent systems used for column chromatography

\begin{tabular}{ccc}
\hline Fractions 1-5 & \multicolumn{1}{c}{ Fractions 6-10 } & Fractions 11-15 \\
\hline Hexane: Ethyl acetate 9:1 & Ethyl acetate: Ethanol 9:1 & Ethanol:Methanol 9:1 \\
Hexane: Ethyl acetate 7:3 & Ethyl acetate: Ethanol 7:3 & Ethanol:Methanol 7:3 \\
Hexane: Ethyl acetate 5:5 & Ethyl acetate: Ethanol 5:5 & Ethanol:Methanol 5:5 \\
Hexane: Ethyl acetate 3:7 & Ethyl acetate: Ethanol 3:7 & Ethanol:Methanol 3:7 \\
Hexane: Ethyl acetate 1:9 & Ethyl acetate: Ethanol 1:9 & Ethanol:Methanol 1:9 \\
\hline
\end{tabular}

Table 2. Total phenolic content of aqueous and ethanolic extracts

\begin{tabular}{ccc}
\hline Extract & $\begin{array}{c}\text { Concentration }(\mathrm{mg} / \\
\mathrm{mL})\end{array}$ & $\begin{array}{c}\text { Phenolic content } \\
(\mathrm{GAE} / \mathrm{mL})\end{array}$ \\
\hline Aqueous & 42.50 & $1826 \mathrm{ppm}$ \\
Ethanolic & 63.925 & $6516 \mathrm{ppm}$ \\
\hline
\end{tabular}

Table 3: Alpha-glucosidase inhibitory activity of aqueous and ethanolic extracts at different concentrations

\begin{tabular}{ccc}
\hline \multirow{2}{*}{ Concentration } & \multicolumn{2}{c}{$\%$ Inhibitory activity } \\
& Ethanolic extracts & Aqueous extracts \\
\hline $100 \mathrm{ppm}$ & $19.55 \pm 3.934$ & $43.65 \pm 1.067$ \\
$500 \mathrm{ppm}$ & $28.16 \pm 1.407$ & $56.14 \pm 2.724$ \\
$1000 \mathrm{ppm}$ & $37.22 \pm 0.644$ & $88.68 \pm 0.665$ \\
$2000 \mathrm{ppm}$ & $59.72 \pm 4.432$ & $100.00 \pm 0.700$ \\
$\mathrm{IC}_{50}$ values & $1560.81 \pm 2.582 \mathrm{ppm}$ & $300.52 \pm 1.467 \mathrm{ppm}$ \\
\hline
\end{tabular}

Table 4: Alpha-glucosidase inhibitory activity of Acarbose, positive control

\begin{tabular}{cc}
\hline Concentration $(\mu \mathrm{g} / \mathrm{mL})$ & Inhibitory activity $(\%)$ \\
\hline 0.01 & $29.97 \pm 4.929$ \\
0.02 & $66.83 \pm 1.932$ \\
0.04 & $78.93 \pm 0.089$ \\
0.06 & $80.24 \pm 2.334$ \\
0.08 & $84.37 \pm 0.385$ \\
0.10 & $94.14 \pm 0.194$ \\
IC50 (Acarbose) & $0.02 \mathrm{ppm} \pm 1.644$ \\
\hline
\end{tabular}

\section{Bio-assay guided fractionation of ethanolic extracts}

Column chromatography yielded 15 fractions from ethanolic extract as well using 15 solvent systems. Table 6 shows the corresponding fraction number, inhibitory activity, Rf value and solvent system used in chromatographic separation. Figure 3 shows the thin layer chromatogram (TLC) of the collected ethanolic fractions.

\section{DISCUSSION}

\section{Total phenolic content}

Table 2 shows that the phenolic content of ethanolic extract is 3.5 times higher $(6516 \mathrm{ppm})$ than the aqueous extract (1826 ppm). Ethanol has a polar and non-polar end which makes it an ideal solvent for the extraction of secondary phytoconstituents such as phenolics since it can extract both polar and non-polar components. The solubility of phenolics in water is also lower compared to ethanol which contributes to more phenolics being extracted by ethanol compared to water.

\section{Alpha-glucosidase inhibitory activity of aqueous and ethanolic extracts}

Results revealed a dose-dependent response because increasing the concentration of ethanolic and aqueous extracts increased the inhibitory activity to $59.72 \%$ and $100 \%$, respectively. Likewise, in terms of half maximal inhibitory concentration $\left(\mathrm{IC}_{50}\right)$ which is the concentration needed for the sample to inhibit $\alpha$-glucosidase by $50 \%$, Table 3 shows that ethanolic extract has a higher IC $_{50}$ value of $1560.81 \mathrm{ppm}$ compared to aqueous extract with $\mathrm{IC}_{50}$ value of $300.52 \mathrm{ppm}$. This suggests that the

\section{Table 5: Inhibitory activity of aqueous fractions}

\begin{tabular}{|c|c|c|c|c|}
\hline $\begin{array}{l}\text { Fraction } \\
\text { number }\end{array}$ & Solvent system & $\begin{array}{c}\% \text { Inhibitory } \\
\text { activity }\end{array}$ & \multicolumn{2}{|c|}{ Rf value } \\
\hline 1 & Hexane: Ethyl acetate 9:1 & -2.058 & \multicolumn{2}{|c|}{0.68} \\
\hline 6 & Ethyl acetate: Ethanol 9:1 & 12.954 & \multicolumn{2}{|c|}{0.70} \\
\hline 9 & Ethyl acetate: Ethanol 3:7 & 38.136 & \multicolumn{2}{|c|}{0.70} \\
\hline 10 & Ethyl acetate: Ethanol 1:9 & 51.695 & \multicolumn{2}{|c|}{0.70} \\
\hline 11 & Ethanol: Methanol 9:1 & 65.012 & \multicolumn{2}{|c|}{0.71} \\
\hline 12 & Ethanol: Methanol 7:3 & 19.492 & \multicolumn{2}{|c|}{0.63} \\
\hline \multirow[t]{5}{*}{13} & \multirow[t]{5}{*}{ Ethanol: Methanol 5:5 } & \multirow[t]{5}{*}{-79.056} & 1 & 0.18 \\
\hline & & & 2 & 0.58 \\
\hline & & & 3 & 0.67 \\
\hline & & & 4 & 0.85 \\
\hline & & & 5 & 0.95 \\
\hline \multirow[t]{4}{*}{14} & \multirow[t]{4}{*}{ Ethanol: Methanol 3:7 } & \multirow[t]{4}{*}{-63.317} & 1 & 0.18 \\
\hline & & & 2 & 0.67 \\
\hline & & & 3 & 0.85 \\
\hline & & & 4 & 0.95 \\
\hline \multirow[t]{3}{*}{16} & \multirow[t]{3}{*}{ Ethanol: Methanol 1:9 } & \multirow[t]{3}{*}{-157.022} & 1 & 0.65 \\
\hline & & & 2 & 0.85 \\
\hline & & & 3 & 0.95 \\
\hline
\end{tabular}

Table 6: Alpha-glucosidase inhibitory activity of ethanolic fractions

\begin{tabular}{|c|c|c|c|c|}
\hline \multirow{2}{*}{$\begin{array}{c}\begin{array}{c}\text { Fraction } \\
\text { number }\end{array} \\
5\end{array}$} & \multirow{2}{*}{$\begin{array}{c}\text { Solvent system } \\
\text { Hexane:Ethyl acetate 1:9 }\end{array}$} & \multirow{2}{*}{$\begin{array}{c}\% \text { Inhibitory } \\
\text { activity }\end{array}$} & \multicolumn{2}{|c|}{ Rf value } \\
\hline & & & 1 & 0.57 \\
\hline & & & 2 & 0.63 \\
\hline & & & 3 & 0.79 \\
\hline & & & 4 & 0.94 \\
\hline \multirow[t]{4}{*}{6} & Ethyl acetate: Ethanol 9:1 & -22.55 & 1 & 0.58 \\
\hline & & & 2 & 0.65 \\
\hline & & & 3 & 0.79 \\
\hline & & & 4 & 0.93 \\
\hline 8 & Ethyl acetate: Ethanol 5:5 & 58.29 & & \\
\hline 9 & Ethyl acetate: Ethanol 3:7 & 65.39 & & \\
\hline 10 & Ethyl acetate: Ethanol 1:9 & 58.01 & & \\
\hline 11 & Ethyl acetate: Ethanol 9:1 & 58.01 & & \\
\hline 12 & Ethanol: Methanol 7:3 & 62.55 & & \\
\hline 13 & Ethanol: Methanol 5:5 & -30.50 & & \\
\hline 14 & Ethanol: Methanol 3:7 & -27.36 & & \\
\hline
\end{tabular}




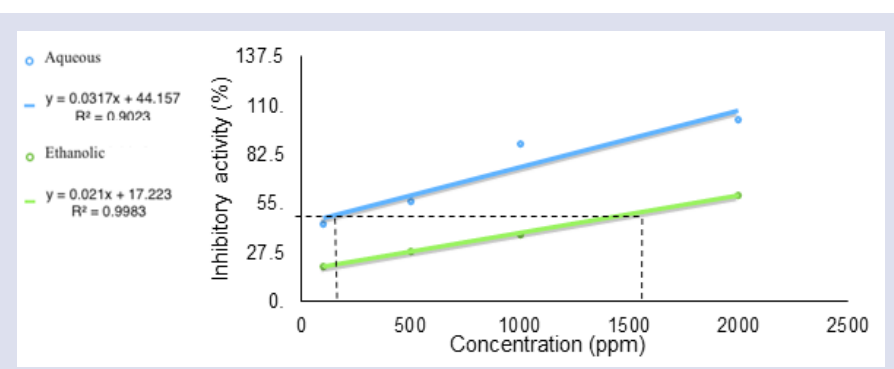

Figure 1: Alpha-glucosidase inhibitory curve of aqueous and ethanolic fractions.

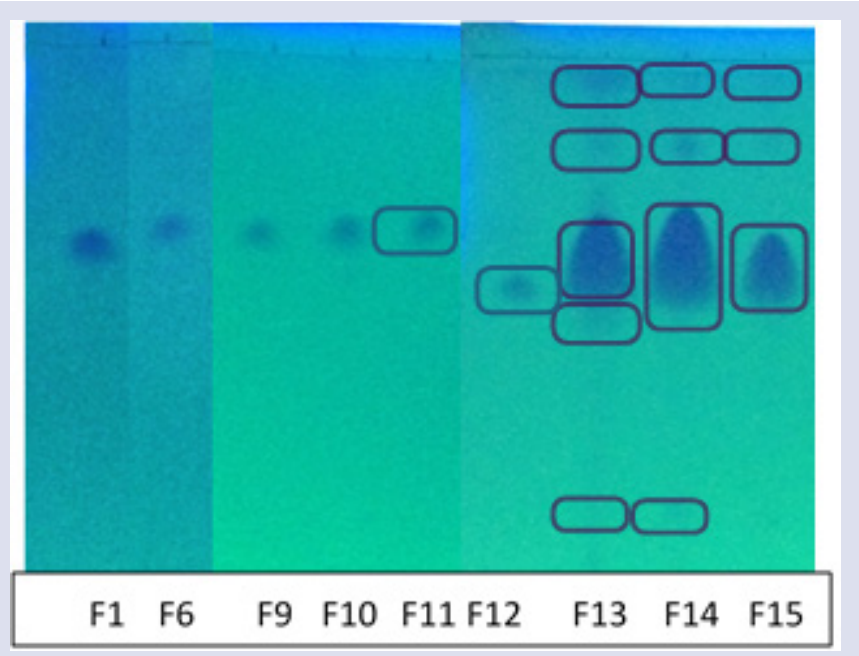

Figure 2: Thin layer chromatogram of aqueous fractions.

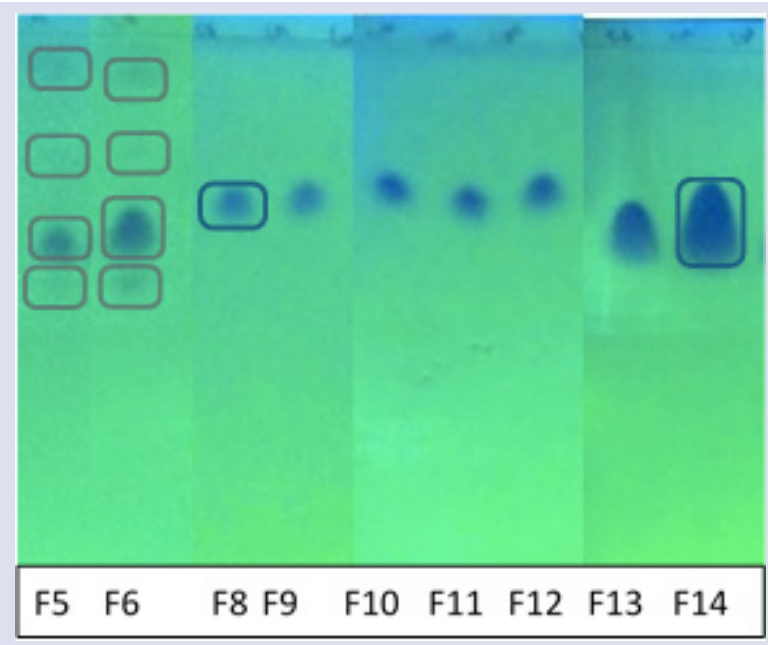

Figure 3: Thin Layer Chromatogram of ethanolic fractions.

inhibitory activity of aqueous extract is higher compared to the inhibitory activity of ethanolic extracts.

Figure 1 shows the linear relationship between concentration and a-glucosidase inhibitory activity of aqueous and ethanolic bark extracts. The increasing inhibitory activity (\%) directly related to the increase in concentration of phenolic compounds implies that there is a dosedependent response of the extract and that the phenolic components in the extract are highly responsible for its a-glucosidase inhibitory activity. This narrows down the possible class of compound which the a-glucosidase inhibitor belongs. In addition, figure 2 also indicates that aqueous extracts generally have higher $\alpha$-glucosidase activity compared to ethanolic extracts. This is consistent with the half maximal inhibitory activity values. This further suggests the polarity of inhibitor compound present in the extract.

\section{Bio-assay guided fractionation of aqueous extracts}

Table 5 shows the increasing $\alpha$-glucosidase inhibitory activity of fractions $1-11$, wherein fraction 11 has the highest inhibitory activity of $65.01 \%$. In addition, TLC of these fractions shows the presence of clear single spots with $\mathrm{Rf}$ value of 0.70 . This suggests the presence of $\alpha$-glucosidase inhibitors separated from other compounds in the extract. Fraction 12 showed a decrease in a-glucosidase inhibitory activity while fractions 13, 14 and 15 show a negative $\alpha$-glucosidase inhibitory activity. This indicates that these fractions no longer contained a-glucosidase inhibitors. TLC of fraction 12 shows a slightly lower spot compared to previous fractions with an Rf value of 0.63 while fractions $13-15$ show multiple spots with Rf values of $0.18,0.58,0.67,0.85$ and 0.95 . Since these fractions were collected in the later part of elution, they may already contain wash residues, pigments and other flow-through components which are not a-glucosidase inhibitors but larger molecules that might mask the activity of the $\alpha$-glucosidase inhibitor activity. Furthermore, in this study, only inhibitory activities of clear fractions were considered, since turbid fractions collected at the later part of fractionation contained background noise that are most likely pigments and wash residues. Multiple possible bioactive and non-bioactive components were identified in the extract using results of bioassay guided fractionation with $\mathrm{Rf}$ values of $0.18,0.58$, $0.63,0.67,0.70,0.85$ and 0.95 .

\section{Bio-assay guided fractionation of ethanolic extracts}

Fractions one to five collected in the early stages of separation showed low inhibitory activity while fraction 6 showed negative inhibitory activity. TLC of these fractions shows a combination of compounds with Rf values of about $0.57,0.63,0.79$ and 0.94 . The negative and low inhibitory activities of these fractions might be attributed to the presence of several compounds in the fraction as observed in the number of spots detected. Ethanolic extract contains more non-polar components compared to aqueous extracts, and these non-polar components might have masked the activity of $\alpha$-glucosidase inhibitors. This is evident in the low and negative inhibitory activities of fractions one to six collected from non-polar solvent systems. Fractions 8 to 12, collected from mid to highly polar solvent systems showed consistently high inhibitory activities with maximum inhibitory activity of $65.39 \%$. In addition, TLC of these fractions show single spots with similar diameter and appearance and with an average $\mathrm{Rf}$ value of 0.70 . Since these fractions possess high $\alpha$-glucosidase inhibitory activity they have high potential as a-glucosidase inhibitors. Fractions 13 and 14 show a decrease in inhibitory activity reaching highly negative values indicating that these fractions do not contain a-glucosidase inhibitors. Similar to purification done with aqueous extracts, fractions collected that were turbid were not considered. TLC of these fractions show a tailing spot with average Rf value of 0.65 . Tailing spot implies poor separation of components which may need alternative solvent system for separation.

\section{Implications}

The search for sources of alpha-glucosidase inhibitors from indigenous plants is a strategy employed in this study to provide an alternative treatment for diabetes mellitus. It was shown from the results presented that the aqueous extract from the barks of Sibucao possessed high inhibitory activity suggesting that water decoctions from the bark maybe enough to extract its medicinal property. This result is also consistent with the $\mathrm{IC}_{50}$ value which measures the activity of the enzyme.

The Rf value of 0.70 for the isolated fraction also indicates the property of the inhibitor that may provide us with information on its potential iden- 
tity and biological properties. Furthermore, the result of this separation is also useful for future characterization of the inhibitory compound.

Taken together, this study has shown evidence of the potential of Sibucao as a natural source of $\alpha$-glucosidase inhibitor for treatment of diabetes and offers an explanation of why local "herbal healers" recommend this plant to remedy the said ailment.

\section{CONCLUSION}

Based on the results obtained, aqueous and ethanolic crude bark extracts of Caesalpinia sappan L. possess promising a-glucosidase inhibitory activity. At 2000 ppm concentration, aqueous extracts show $100.00 \%$ and ethanolic extracts show $59.72 \%$ inhibition. Generally, aqueous extracts have higher enzyme inhibition activity compared to ethanolic extracts. In terms of half maximal inhibitory activity $\left(\mathrm{IC}_{50}\right)$, aqueous extracts have $\mathrm{IC}_{50}$ of $300.52 \mathrm{ppm}$ and ethanolic extracts have $\mathrm{IC}_{50}$ of $1560.81 \mathrm{ppm}$. Partial fractionation and testing of bioactive compounds revealed the appearance of 7 peaks for aqueous extracts with Rf values of $0.18,0.58$, $0.63,0.67,0.70,0.85$ and 0.95 and 6 peaks for ethanolic extracts with $\mathrm{Rf}$ values of $0.57,0.63,0.67,0.70,0.79$ and 0.93 . Both aqueous and ethanolic extracts contain compound with $\mathrm{Rf}$ value of 0.70 , this compound shows positive inhibitory activity of $65 \%$. Results from this study can be used as a reference tool for future isolation and characterization of $\alpha$-glucosidase inhibitors.

\section{ACKNOWLEDGEMENT}

This study would like to acknowledge the support of the Tuklas Lunas Research and Development Center, Visayas State University. We would also like to acknowledge the contributions of Dr. Felix M. Salas, Dr. Candelario L. Calibo, Prof. Jacob Glenn F. Jansalin, Mr. Ronald Arlet P. Villaber and Ms. Marciana B. Galambao. In addition the authors would also like to thank Ms. Zenaido Ecleo for her technical support and assistance during the conduct of the study.

\section{CONFLICTING INTEREST}

This study has no conflict of interest.

\section{ABBREVIATIONS USED}

TLC: Thin Layer Chromatography; $\mathrm{IC}_{50}$ : Half Maximal Inhibitory Activity; PNPG: 4-Nitrophenyl $\alpha$-D-glucopyranoside; DMSO: Dimethylsulf- oxide; Abs: Absorbance; a-glucosidase: Alpha-glucosidase; Rf values: Retention Factor values.

\section{REFERENCES}

1. Mcculloch D, Nathan D, Mulder J. Patient information: Diabetes mellitus type 2:Treatment (Beyond the Basics). Up to date [Internet] Available from: http:// www.uptodate.com/contents/diabetes-mellitus-type-2-treatment-beyond-thebasics

2. Lee SS, Lin HC, Chen CK. Acylated flavonol monorhamnosides, $\alpha$-glucosidase inhibitors, from Machilus philippinensis. Phytochem. 2008;69(12):2347-53. https://doi.org/10.1016/j.phytochem.2008.06.006; PMid:18639907.

3. Del fierro RS, Nolasco FA. An exploration of the ethno-medicinal practices among traditional healers in southwest cebu, philippines. APRN Journal of Science and Technology. 2013;3:1184-86.

4. Wake up Philippines [Internet]. Erineus. 2009. Health benefits of Sappan wood Alternative medicine [cited: May 19, 2014]. Available from: https://wakeuphils. wordpress.com/tag/sibucao/

5. Jyothi KS, Hemalatha P, Challa S. Evaluation of $\alpha$-amylase inhibitory potential of three medicinally important traditional wild food plants of India. International journal of green pharmacy. 2011;5(2):95-9. https://doi.org/10.4103/09738258.85158.

6. Singleton VL, Orthofer R, Lamuela-raventos RM. Analysis of total phenols and other oxidation substrates and antioxidants by means of Folin-ciocalteu reagent. Methods Enzymol. 1999;299:152-78. https://doi.org/10.1016/S00766879(99)99017-1.

7. Kim J, Yang J, Kim M. Alpha glucosidase inhibitory effect, anti-microbial activity and UPLC analysis of Rhus verniciflua under various extract conditions. Journa of Medicinal Plant Research. 2011;5(5):778-83.

8. Shiny C, Saxena A, Gupta S. Phytochemical investigation of the insulin plant "Costus pictus" D. Don. International J Pharm Biomed Res. 2013;4:97-104.

9. Fao.org [Internet]. _ [cited: March 11, 2016] Available from: http://www.fao.org/ docrep/X5036E/x5036E0p.htm.

10. Kumar S, Narwal S, Prakash O. $\alpha$-glucosidase inhibitors from plants: A natural approach to treat diabetes. Pharmacognosy Review 2011;5(9):19-29. https://doi. org/10.4103/0973-7847.79096; https://doi.org/10.1016/S0975-3575(11)80021-0.

11. Hanamura T, Hagiwara T, Kawagishi H. Structural and functional characterization of polyphenols isolated from acerola (Malpighia emarginata DC.) fruit. Biosci Biotechnol Biochem 2005;69:280-6. https://oi.org/10.1271/bbb.69.280; PMid:15725651.

12. Thilagam E, Parimaladevi B, Kumarappan C, Mandal SC. $\alpha$-Glucosidase and $\alpha$-amylase inhibitory activity of Senna surattensis. J Acupunct Meridian Stud. 2013;6:24-30. https://doi.org/10.1016/j.jams.2012.10.005; PMid:23433052

13. Song Y, Manson JE, Buring JE, Sesso HD, Liu S. Associations of dietary flavonoids with risk of type 2 diabetes, and markers of insulin resistance and systemic inflammation in women: a prospective study and cross-sectional analysis. J Am Coll Nutr 2005;24(5):376-84. https://doi.org/10.1080/07315724.2005. 10719488; PMid:16192263.

\section{SUMMARY}

- Alpha-glucosidase inhibitory activity of aqueous extracts were determined.

- $\mathrm{IC}_{50}$ value = $300.52 \pm 1.467 \mathrm{ppm}$

- Alpha-glucosidase inhibitory activity of ethanolic extracts and $I \mathrm{C}_{50}$ were determined.

- $\mathrm{IC}_{50}$ value $=1560.81 \pm 2.582 \mathrm{ppm}$

- Partial fractionation was done using column chromatography to isolate bioactive compounds. 15 solvent systems were used, collecting fifteen $1 \mathrm{~mL}$ fractions from each extract.

- Bioactivity of each fraction was determined by measuring the $\alpha$-glucosidase inhibitory of each fraction.

- Active compounds were analyzed using Thin Layer Chromatography and Rf values were measured.

- Compound with Rf value of 0.70 had the highest $\alpha$-glucosidase inhibitory activity of $65 \%$ for aqueous and ethanolic extracts.

\section{ABOUT AUTHORS}

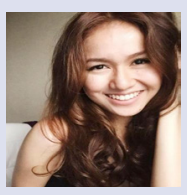

Ea Kristine Clarisse Tulin: Is an Instructor at the Department of Biotechnology of the Visayas State UniversityBaybay City, Leyte, Philippines. She graduated Bachelor of Science in Chemistry at the same university. For her undergraduate thesis she worked on a diabetes related study which involved the evaluation of the alpha-glucosidase inhibitory activity of natural products, specifically Caesalpinia sappan L. bark extracts, commonly known as Sibucao.

Cite this Article: Tulin EKCB, Loreto MTP, Tulin EE. Alpha-Glucosidase Inhibitory Activity and Fractionation of Bioactive Compounds from bark Extracts of Sibucao (Caesalpinia sappan L.) In the Philippines. Pharmacogn J. 2017;9(3):356-60. 